\title{
Hendidura de velo posterior que simula una válvula mitral de tres velos
}

\author{
Julián Vega, Andrés Kanacri, Luigi Gabrielli, Samuel Córdova, Gabriel Olivares. \\ División de Enfermedades Cardiovasculares. Pontificia Universidad Católica de Chile \\ Laboratorio de Ecocardiografía y Sección de Cirugía Cardíaca. División de Enfermedades \\ Cardiovasculares. Facultad de Medicina, Pontificia Universidad Católica de Chile
}

Resumen: Reportamos el caso de una mujer de 55 años, que completo terapia antibiótica por una periodontitis con buena respuesta clínica. Posteriormente, presentó fiebre y dolor lumbar, hospitalizándose para estudio. Destacaban parámetros inflamatorios elevados y hemocultivos positivos para Streptococcus Viridans. Estudio de imágenes confirmaron espondilodiscitis de L5-S1. Se efectuó un Ecocardiograma transesogáfico (ETE), que mostró una válvula mitral de aspecto tricúspide, con prolapso del velo posterior (P2-P3) e insuficiencia severa, más una endocarditis mural auricular izquierda por lesión de jet. Se efectuó cirugía cardíaca con reparación mitral. Los hallazgos intraoperatorios mostraron el aparato subvalvular y músculos papilares habituales. Por lo tanto, el aspecto de la válvula mitral fue interpretado como una hendidura profunda del velo posterior. 


\section{Cleft of the posterior mitral valve leaflet simulating a three leaflet valve}

We report the case of a 55 year old woman, previously treated with antibiotics for periodontitis. She was admitted with fever and lumbar pain. An elevated C reactive protein (CRP) and positive blood cultures for Streptococcus Viridans were found and infectious spondylodiscitis of L5-S1 was confirmed. Transesophageal echocardiography (TEE) was performed. A tri-leaflet mitral valve and prolapse of posterior leaflet (P2-P3) were found and severe mitral regurgitation

Reportamos el caso de una mujer de 55 años que el mes previo a la consulta, recibió tratamiento antibiótico por periodontitis con buena evolución clínica.

Consultó por cuadro de 2 semanas de fiebre y dolor lumbar, fue hospitalizada para estudio, destacando parámetros inflamatorios elevados y hemocultivos positivos para Streptococus viridans. El estudio de imágenes fue compatible con espondilodiscitis de L5-S1. Se efectuó ecocardiotransesogáfico (ETE) que mostró una válvula mitral con prolapso del velo posterior (P2-P3), sin poder clarificar de buena forma la anatomía valvular, ni el mecanismo was present on doppler examination In addition, a left atrial mural vegetation (jet lesion) was found. At cardiac surgery mitral valve repair and resection of the mural vegetations were performed. The papillary muscles were normal, and this tri-leaflet aspect of the mitral valve was interpreted as a deep posterior cleft with symmetrical distribution of all remaining segments.

Key Words: Endocarditis, Mitral valve prolapse, mitral valve insufficiency

responsable de la regurgitación por Ecocardiograma 2D (Figura 1). El Doppler constató una insuficiencia severa excéntrica (Figura 2). Además, se observó una imagen sugerente de vegetación mural en la aurícula izquierda en relación a sitio de impacto del jet de reflujo mitral.

Las imágenes en 3D en tiempo real evidenciaron una válvula mitral de tres velos, con distribución y orientación simétrica de los mismos (Figuras 3 y 4). Además, existía un prolapso del velo en situación postero-medial (Figura 5). Bajo tratamiento antibiótico se efectuó cirugía cardíaca con reparación de la válvula mitral, resección triangular 
del velo postero-medial y cierre en línea media del velo posterior más anuloplastía con banda Duran N²9. Además, se resecó la vegetación mural auricular.

Los hallazgos intraoperatorios mostraron el aparato subvalvular y músculos papilares normales, interpretando la estructura de la válvula mitral como una hendidura profunda del velo posterior. Este es un hallazgo muy infrecuente, con una prevalencia del $0.11 \%$ en una serie de, aproximadamente, 20.000 ecocardiografías de superficie $^{1}$, siendo reportada su semejanza con una válvula mitral de tres velos genuina ${ }^{2}$. Esta patología se ha reportado tanto en la edad adulta en el contexto de miocardiopatía hipertrófica ${ }^{3}$ y membranas subaórticas ${ }^{4}$, como en la edad pediátrica, como una anomalía aislada y que puede ocasionar obstrucción al tracto de salida del ventrículo izquierdo y muerte súbita 5 .

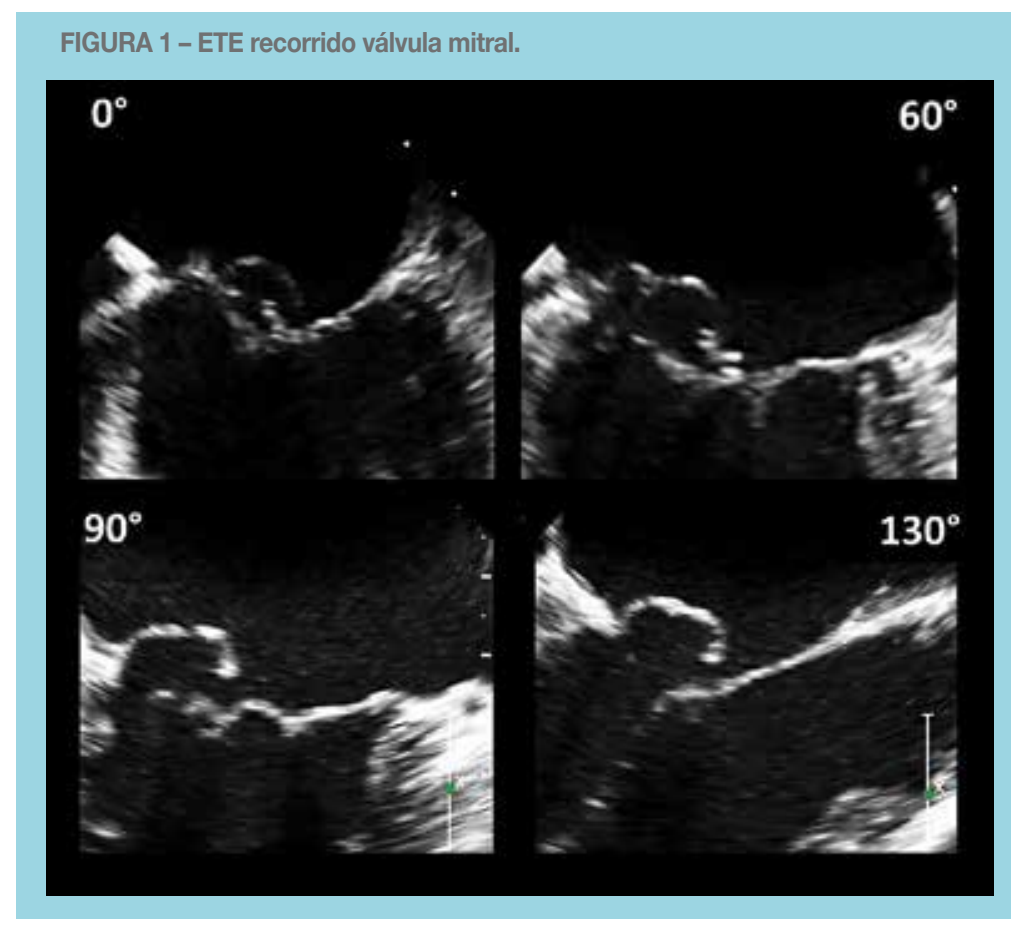

FIGURA 2 - ETE Visión eje largo con prolapso de P2 e insuficiencia mitral severa.

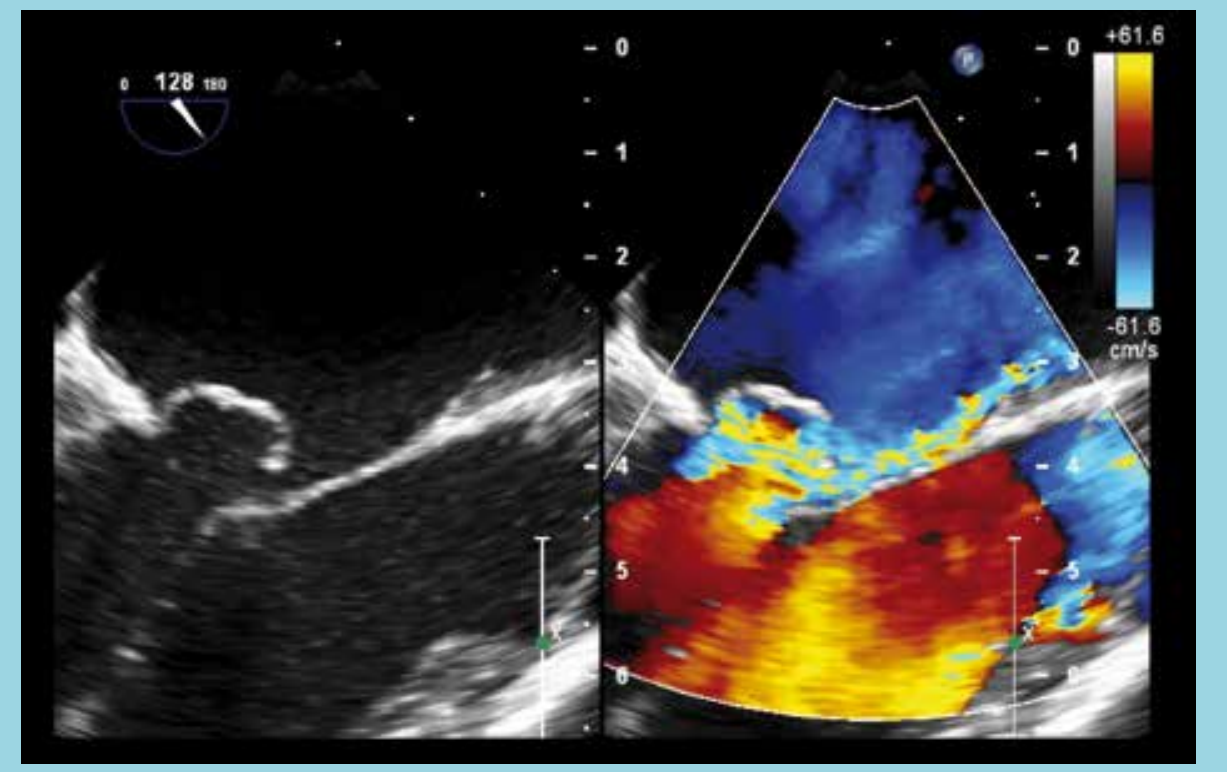


FIGURA 3, ETE3D Tiempo Real. Válvula Mitral desde la cara ventricular.

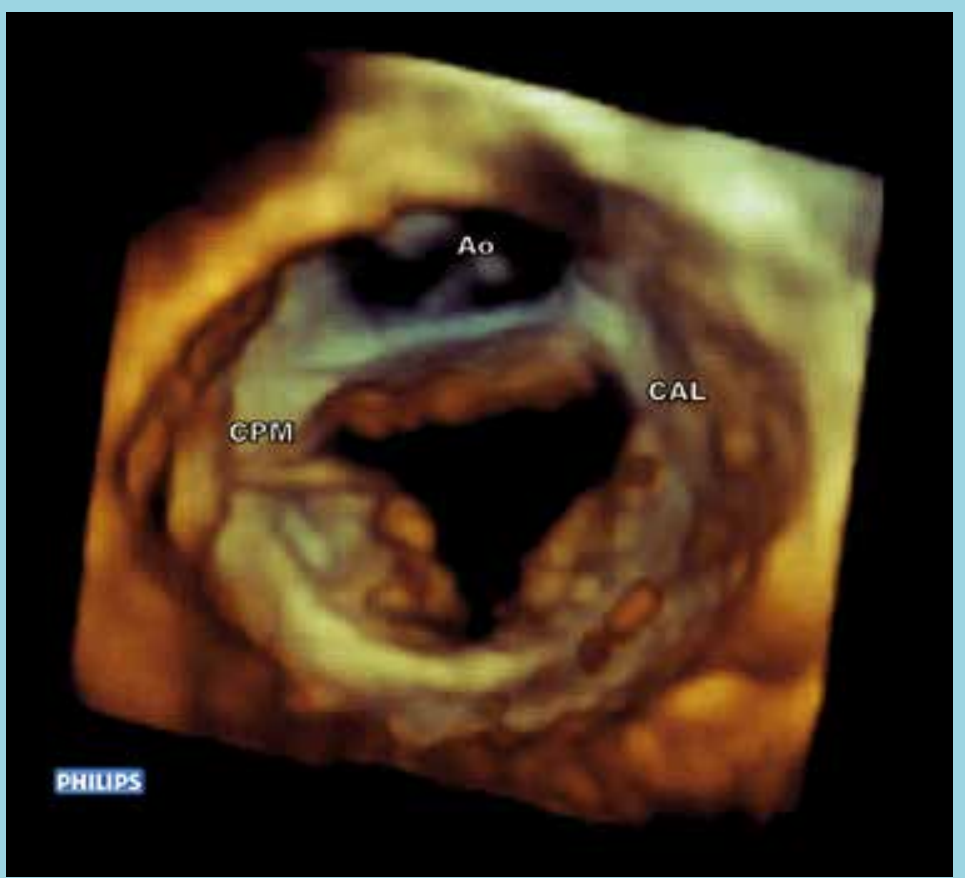

Leyenda: CAL: Comisura antero-lateral, CMP: Comisura postero-medial, Ao: Aorta.

FIGURA 4, ETE 3D Tiempo Real, Válvula Mitral desde la cara auricular (vista "EN FACE").

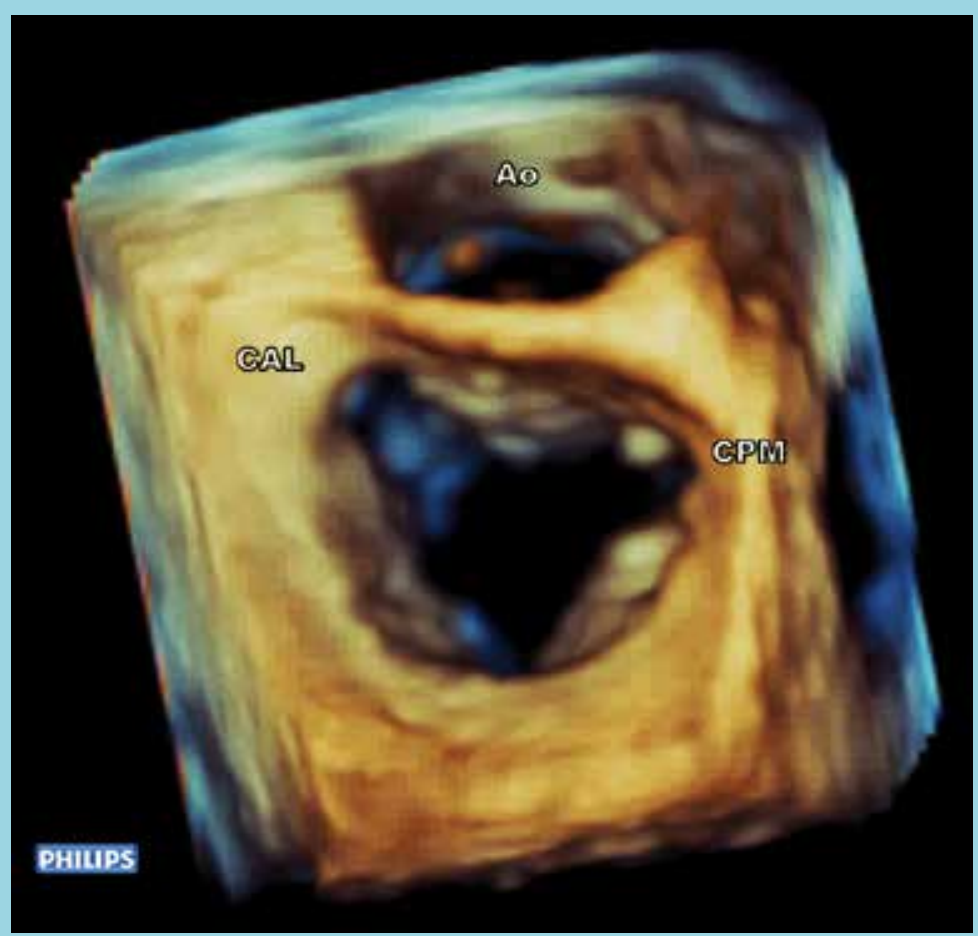

Leyenda: CAL: Comisura antero-lateral, CMP: Comisura postero-medial, Ao: Aorta. 
FIGURA 5, ETE 3D Tiempo Real, Válvula Mitral en sístole, destaca el prolapso del velo postero-medial

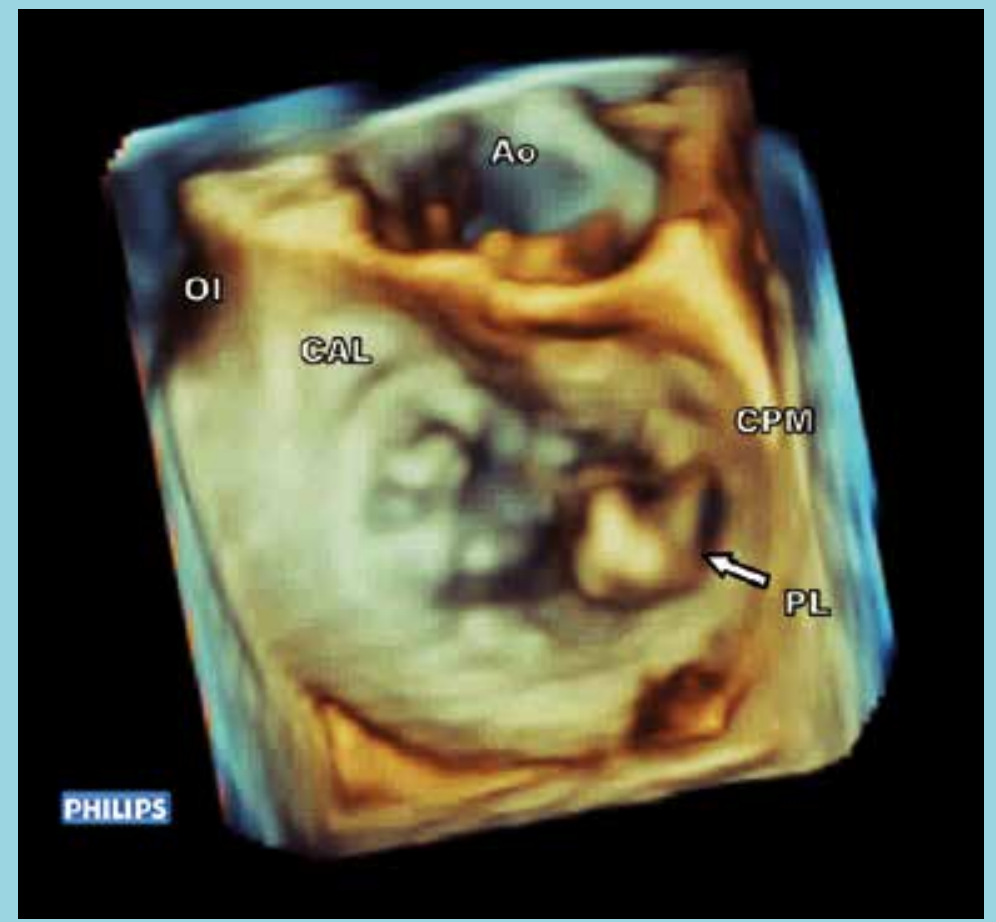

Leyenda: CAL: Comisura antero-lateral, CMP: Comisura postero-medial, Ao: Aorta, Ol: Orejuela izquierda, PL: Prolapso.

\section{Referencias:}

1. WYSS CA, ENSELEIT F, VAN DER LOO B, GRÜNENFELDER J, OECHSLIN EN, JENNI R. Isolated cleft in the posterior mitral valve leaflet: a congenital form of mitral regurgitation. Clin Cardiol. 2009; 32: 553-60.

2. VIGNALOU JB, EWE SH, SCHALIJ MJ, BAX JJ, DELGADO V. Isolated posterior mitral leaflet cleft resembling trileaflet valve. Eur Heart J Cardiovasc Imaging. 2012; 13: 535.

3. ROSANIO S, SIMONSEN CJ, STARWALT J, KEYLANI AM, VITARELLI A. Trileaflet Mitral Valve with Three Papi- llary Muscles Associated with Hypertrophic Cardiomyopathy: A Novel Case. Echocardiography. 2015 32: 1435-7.

4. KOZAK MF, SIVANANDAM S, DE MARCHI CH, KOZAK AC, CROTI UA, MOSCARDINI AC, et al. A trileaflet "mitral valve" with three papillary muscles: brand new echocardiographic finding. Congenit. Heart. Dis. 2011; 6: 70-3.

5. ESPINOLA-ZABALETA N, YABUR-ESPITIA M. Congenital mitral valve anomalies in adults. Clinical and echocardiographic study. Arch Cardiol Mex. 2010; 80: 113-8. 